\title{
HITTILISTAN KIEHTOVA BANAALISUUS
}

Same as it ever was... (David Byrne)

Hittilista - popmusiikki $\bullet$ menestystarina - modernisuus $・$ muoti $\bullet$ muoto $\bullet$ elämäntapa - maku - esteettinen viehätys - ainutkertaisuus - tavanomaisuus • banaalisuus • laiskuus $\cdot$ ikävystyminen $\cdot$ vanheneminen $・$ kuolema

Hittilista tai vastaavankaltainen järjestelmä, jota lehdet ja radio säännöllisesti (päivittäin, viikoittain, kuukausittain...) julkaisevat, on lăhes universaali ilmiö populaarimusiikin maailmassa. Ja vaikka tällaisia kvantitatiivisia levymyynnille, levyautomaateille tai postiäänestykselle perustuvia sijaluetteloja ei yhteiskunnassa levitettäisikään, implisiittiset hierarkiat - kuten juuri lyhytaikaisten suosikkikappaleiden nopea vaihtuminen ja vuorottelu listalla - kuuluvat silti piilevänä kulutusyhteiskuntaamme. Nykyiset hittilistat ovatkin luonteenomaisia populaarimusiikille siksi että "maun heilahtelut" (Gillo Dorfles) kannattajakunnan keskuudessa ovat nopeita; näin ne kuvastavat ilmiötă nimeltä "muoti". Populaarimusiikki tai paremminkin popmusiikki (tai rock'n roll amerikkalaisessa mielessä) on väistämättä yhteydessä muodin muutoksiin. Tämä merkitsee, että popmusiikkia voidaan vastaanottaa, levittää ja kuluttaa eri tavalla kuin alkuperäistai primitiivistä musiikkia vähemmän kapitalistisessa yhteiskunnassa ja klassista musiikkia länsimaisessa yhteiskunnassa. Tietysti näidenkin musiikkien tyylinmuutokset ja sosiaalinen hyväksyntä riippuvat yleisön mausta ja esteettisestä arvioinneista, mutta muutoksen nopeus on näissä kuitenkin huomattavasti hitaampi kuin popmusiikissa - ei ainoastaan määrällisesti (kuten empiirinen tutkimus voisi osoittaa) vaan myös laadullisesti kuten jatkossa havaitsemme.

Hittilistojen "koneisto" ei siis ole popmusiikin seurannaisilmiö vaan välttämätön ehto popmusiikin ontologisen aseman vakiinnuttamiselle musiikillisessa kulutusyhteiskunnassamme. Vakiokappaleet, sellaiset kuin Yesterday ja Bridge over Troubled Water eivät - huolimatta ikivihreydestään tai pysyvästä suosiostaan ja uusien albumiversioidensa määrästä - ole vaikuttamassa popmusiikin voimalliseen kehitykseen ja hurjaan lisääntymiseen; standardisävelmien tehtävä on ainoastaan ylläpitää popkulttuurin keskeistä ja pysyvää perustaa - 
tislatussa ja puhdistetussa muodossa. Ne ovat kivettyneitä, muumioituneita ja haalistuneita: ne ovat popmusiikin vinylisoitu museo. Kuten I. Chambers huomauttaa, musiikillisen "nykyisyyden" korostuminen jokaisella tasolla - ei vain musiikillisella vaan myös fyysisellä, visuaalisella, älyllisellä ja niin edelleen - on "ratkaisevaa popkulttuurille" $(1985,210)$. Hittilista musiikillisen modernisuuden ilmaisijana ei ole popmusiikin liite tai lisäke, vaan se on popin kulttuurinen - eikä siis vain välttämätön ja taloudellinen - ydin. Hieman kärjistäen voisimmekin määritellä popmusiikin musiikin tuottamiseksi ja kuluttamiseksi hittilistojen myötävaikutuksella. Siten popmusiikilla ei ole menneisyyttä, ei tulevaisuutta, ei säilyvyyttä: se on musiikkia tätä viikkoa, tätä päivää ja tätä hetkeä varten.

Tämä ei tarkoita, että kyseinen musiikki aktuaalistuisi - kuten fenomenologiset lähestymistavat (esim. A. Schutz) selittävät - ainoastaan silloin kun sitä kuunnellaan ja se "eletään", vaan sitä että popkappaleilla on tavallisesti yhtä lyhytaikainen sosiokulttuurinen elämä kuin muotivaatteilla. Popmusiikin ja muodin välinen korrelaatio - beatlesit ja minihame, punk ja nahka-asu, folk-rock ja farkut jne. - ei siis ole lainkaan sattumaa. (Cabaret Voltaire -yhtyeen keikalta löytyy tuskin yhtään poninhäntäistä tyttöä). Popmusiikki on niin perinpohjaisesti faniensa elämäntavan kyllästämää, ettei nuorison elämäntapaa voi kuvata ottamatta huomioon myös yleistä musiikkisuuntausta. Tietysti musiikkityylin ja elämäntavan, musiikillisen reseption ja sosiaalisen rakenteen välistä vastaavuutta voidaan tarkastella myös klassisen tai etnisen musiikin tapauksissa. Mutta juuri popmusiikin tutkimuksessa näyttäisi olevan tärkeää saada käsitys kiihtyvästä "elämänmenosta" kuin myös vahvistaa tuo vastaavuus; toisin sanoen se miten maut voivat muodostua toinen toisensa jälkeen niin nopeaan tahtiin, mikä aiheuttaa nuo musiikki- ja elämäntyylin perättäiset, pakkomielteenomaiset ja joskus agressiiviset muutokset ja mutaatiot, mistä mainstream ja "keskitien" popmusiikki muodostuvat, mitä mainstreamin käsite tarkoittaa ja miksi jopa iso hitti putoaa listalta niin nopeasti.

Saksalaisen sosiologian pioneerin Georg Simmelin tärkeä essee muodista, joka julkaistiin vuonna 1911 (Philosophische Kultur), on edelleen ajatuksia herättävä; siihen kannattaa viitata tässä - siitäkin huolimatta että sosiaalinen rakenne ja kulttuuri ovat suuresti muuntuneet erityisesti langattomien tiedotusvälineiden kuten radion, television jne. synnyn ja leviämisen myötä. Simmelin mukaan elämä ilmiönä muodostuu kahdesta vastakohtaisesta elementistä, sosiaalisesta yhtenäisyydestä ja yksilöllisestä erilaisuudesta: "Sitominen ja erottaminen ovat tässä kaksi perusfunktiota, jotka ovat lähtemättömästi kietoutuneet toisiinsa..." (ibid., 29). Yhtäältä pyrkimys matkia ja jäljitellä muita ihmisiä takaa yhtenäisyyden ja keventää näin käyttäytymiseen liittyvää henkilökohtaista ja yksilöllistä vastuuta; ja toisaalta päinvastainen pyrkimys erottua muista (toisesta henkilöstä, luokasta, ryhmästä...) vetää rajan minun ja sinun, meidän ja heidän välille henkilökohtaisella, sosiaalisella ja/tai sukupuolten tasolla. Muoti edustaa tätä sosiaalisen elämän dualistista rakennetta, koska se samanaikaisesti sekä sulkee sisäänsä ja että jättää ulkopuolelleen: se ruokkii kunkinhetkisen pukeutumistyylin kannattajien yhteenkuuluvuuden tunnetta ja ulkoista eristäytymistä tarkoituksenaan lujittaa kannattajakunnan 
yleismaailmallista sosiaalista asemaa. Simmel käsittelee kirjoituksessaan tuota kaksijakoisuutta pikemminkin psykologisesta (tai sosiaalipsykologisesta) kuin historiallisesta tai empiirisestä näkökulmasta, ja hän asettaa muodin muodon sen sisällön edelle: "Muotien historiaa on tăhän asti tutkittu vain niiden sisältöjen kannalta, mutta jos sitä tutkitaan siltă kannalta, mikä on niiden merkitys yhteiskunnallisen prosessin muodon kannalta, niin se on historia, joka kuvaa yrityksiä tyydyttää noita vastakkaisia pyrkimyksiä yhä täydellisemmin kulloisenkin yksilöllisen ja yhteiskunnallisen kulttuurin tilaa vastaavalla tavalla" (Simmel ibid., 29). Simmelin "formalistinen" ajattelutapa on hyvin tärkeä, kun mietitään hittilistojen - eikä vain muodin - mekanismia numeerisena ja nominaalisena rakenteena (ks. jäljempänä), koska hittilistan paremmuusjärjestys liittyy pohjimmiltaan sävelmän formaaliseen puoleen eikä sen sisältöön.

Hittilista on musiikille samaa kuin muoti vaatteille. Hittilistassa on vain se ero, että siinä kappaleiden senhetkinen järjestys ja niiden nimet ja sijaluvut tulevat selvemmin esille kuin vaatemuodissa. Toisaalta populaarimusiikkiin, kuten muotiinkin vaikuttaa kaksi ristiriitaista voimaa, jotka ovat sävelmän sisäja ulkopuolella: banaalisuus ja ainutkertaisuus. Meidän on toisin sanoen käytettävä kahta yhteenkietoutunutta käsitettä, banaalia jonka pohjana on ainutkertainen sekä ainutkertaista jonka pohjana on banaali. Nämä eivät ole kaksi erillistä kokonaisuutta vaan kaksi ääripäätä esteettisten arvostelmien jatkumossa. Tämä tarkoittaa että esteettisten arvostelmien kentässä ei ole banaalisuutta tai ainutkertaisuutta puhtaassa muodossa; nämä suureet ovat pikemmin "tendenssejä" kuin "entiteettejä", pikemmin jatkuvuuksia kuin epäjatkuvuuksia. Banaali tuottaa musiikin kenttään tavanomaisuuden kun taas ainutkertainen tuo siihen erikoisuuden. Nämä kaksi toisiaan täydentävää piirrettä ovat yhtä lailla välttämättömiä kappaleelle, jotta se sijoittuisi hittilistalle, koska listan numerojärjestys osoittaa kappaleiden keskinäisen tasapainon, ja tämä on tasapainoa tutun ja oudon, tunnetun ja tuntemattoman välillä. Hittilistan vaihtuva asu ja kunkin kappaleen selvät nousut ja laskut listalla ovat seurausta loputtomasta prosessista, jossa ainutkertaisesta tulee banaalia, oudosta tuttua ja uudesta vanhaa.

Kappaleiden heilahtelua listalla eivät määrää yksin muutokset yleisön musiikkimaussa, vaan siihen vaikuttavat myös "fanien tunnesiteiden sisäinen artikulaatio rock'n roll- koneistossa" (Grossberg). Niinpä hittilistojen ymmärtäminen ei ole vain sitä että tajuaa nuo "tunnesiteet" aidossa psykologisessa vuorovaikutuksessa kuuntelijan ja häntä kiehtovan hitin välillä, vaan että myös tunnistaa nuo tunnesiteet modernismin ja kenties jälkimodernismin avainsanoiksi; tässä kapitalistinen peli ja kilpailu sekoittuvat toisiinsa ja tekevät uutuuspyrkimysten taistelusta olemassaolon taistelua: siinä vain uusi voi tulla kysymykseen. Simmel kutsui tätä tuotteeseen kohdistuvan esteettisen arvioinnin tai esteettisen asenteen muotoa esteettiseksi viehätykseksi (ästhetische Reiz). Hänen mukaansa lyhytaikaisuus, hetkellisyys ja muuttuvuus ovat luonteenomaisia modernismille, joka syntyi juuri teollisen vallankumouksen ja sen aiheuttamien teknisten ja urbaanisten muutosten myötä. Voimmekin määritellä, että viehätys on yksi reseption muoto, joka kestää suhteellisen lyhyen aikaa, mutta huipentuu sitäkin korkeammalle tasolle: hetkelliseksi kliimaksiksi, 
lyhytaikaiseksi kiihkon huipuksi, joka kytkee voimakkaat tunnesiteet ja intohimoimpulssit päälle. Simmel toteaa:

Modernille elämälle ominainen kärsimätön tempo ei merkitse vain halua elämän laadullisten sisältöjen nopeampaan vaihteluun vaan myös rajakohdan alun ja lopun, tulemisen ja lähtemisen - formaalisen kiihotuksen voimaa. Tuo muoto ilmenee tiukimmassa mielessä muodissa. Samanaikaisella laajenemisellaan ja tuhoutumisellaan leikittelevälle muodille on luonteenomaista tuo rajakohdan erikoislaatuinen kiihotus, samanaikaisen alkamisen ja loppumisen, uutuuden ja katoavaisuuden houkutus. Sen kysymys ei ole ollako vai eikö olla vaan samanaikainen olla ja ei-olla. Se seisoo aina menneisyyyden ja tulevaisuuden vedenjakajalla ja antaa meille, niin kauan kuin se on voimissaan, niin vahvan nykyhetken tunteen (Gegenwartsgefühl) jonka vain harvat ilmiöt kykenevät antamaan. (ibid. 35).

Simmel korostaa tässä aivan oikein houkutusvoiman kaksijakoista asemaa nykyisyyden aika-akselilla (Neuheit und Vergänglichkeit) sekä ontologisella tasolla (Sein und Nichtsein). Muoti ei ole siis muuta kuin olemista, joka on katoamassa, vetäytymässä pois todellisuuden piiristä tai tulemassa siihen, eiolemista joka on tulossa näkyviin olemiseksi. Ainoastaan sen "jälkiä" voidaan löytää jälkeenpäin ja jopa etukäteen (esimerkiksi hittilistan "luotisymboli", joka ennustaa tulevaa järjestystä listalla ja perustuu markkinatutkimukseen tai toimittajan intuitioon tai tuotantopaineisiin...).

Modernismi on viehätyksen aikakausi mutta myös samalla uuden aikakausi, aivan kuten saksankielen Neuheit tarkoittaa sekä uudenaikaisuutta että uutuutta, jossa lakkaamatonta uuden, tuntemattoman ja alkuperäisen etsintää pidetään oikeutettuna. R. Barthesin ja J.-L. Bouttesin mukaan tämä suuntaus syntyi vasta 1700-luvun lopulla, jolloin kuuluisa querelles entre les anciens et les modernes päätyi jälkimmäisten voittoon (1979, 580; ks. myös Campagnon 1978, 293). Syntyi "neomania", jolloin uutuus, jamais vu (ennennäkemätön) ja jamais écouté (ennenkuulematon) arvioitiin paremmaksi kuin vanha, toistettu ja banaali. Uutuus, alkuperäisyyden synonyyminä, muuttui "autenttisuudeksi", ja siitä tuli uusi arvokäsite, jolla arvioida taiteellisia objekteja. Historiallinen tietoisuus, yhdessä sen tiedon kanssa että menneeseen oli mahdotonta palata, vahvisti romantiikan aikana yhtäältä alkuperäisyyden (origine) kulttia sen puhtaimmassa muodossa ja toisaalta rohkaisi kaipuuta taideteoksen "auraan" tai "sädekehään". Aikaulottuvuudesta tuli nyt esteettisen arvioinnin tärkeimpiä tekijöitä. Kun uusi on aina luonnostaan ja väistämättä pakotettu vanhenemaan ja siten toistumaan ja arkipäiväistymään, aiheutuu tästä muutos esteettisessä arvioinnissa, ja nykyään tämä muutos tapahtuu - lähinnä äänentoistolaitteiden kehityksen vuoksi - yhä nopeammin ja nopeammin. Barthes ja Bouttes kirjoittavat:

... uudet propositiot tuotetaan aluksi protestiksi aiemmille tavanomaisuuksille, mutta siitä hetkestä lähtien kun näistä paradoksaalisista propositioista alkaa tulla tärkeitä, tietty joukko tuntemattomia sanankäyttäjiä omaksuu ne, ja niistä 
vuorostaan tulee tavanomaisuuksia, joista halutaan pääst eroon taas uusien propositioiden avulla ja niin edelleen (Barthes \& Bouttes 1979, 581).

Barthesin ja Bouttesin esittämä tavanomaisuuksien syntyprosessi selittää samalla myös kuinka esteettinen viehätysvoima syntyy niin kulttuurisesti kuin affektiivisestikin. Toisin sanoen viehätys ei ole sävelmän temporaalisen - siis syntaktisen - rakenteen jatkuvaa lukemista minkä Adorno määrittelee "strukturaaliseksi kuunteluksi", vaan se on soundin, soinnin hetkellistä alistamista globaaliselle, välittömälle ymmärtämiselle. Voidaan tietysti kysyä, onko "soundi" tavanomainen vai ei, toisin sanoen protestoiko se aiempaa vastaan ja siten eroaa siitä, jolloin vanhaa voidaan arvioida välittömästi ja affektiivisesti ilman älyllistä tutkintaa. Tavanomaisuus toimii sekä negatiivisena että positiivisena tekijänä (se on toisaalta hylättävä, jotta se voisi antaa tilaa uudelle ja ennen esiintymättömälle, mutta toisaalta se tarjoaa kriteerin välittömälle esteettiselle arviolle).

Tämä tavanomaisuuksien ambivalenssi - mikä liittyy edellä mainittuun sosiaalisen elämän ja hittisävelmän kaksinaismuotoon - on olennainen osa hittilistan olemusta; sitä korostaa ja sille antaa yleistä kantavuutta joukkotiedotusvälineiden aikakauden tuleminen kaksi vuosikymmentä Simmelin artikkelin jälkeen. Barthes ja Bouttes osuvat oikeaan kutsuessaan joukkotiedotusvälineitä "tavanomaisuuden ainoaksi ja oikeaksi Olympukseksi" (ibid., 581). Juuri Benjaminin määrittelemä "reproduktiotekniikka", joka edesauttaa esteettistä objektia toistamaan itseään täydellisesti, kiihdyttää edellä mainittujen erilaisten tavanomaisuuksien vaihtumisnopeutta ja banalisoi näin ainutkertaisen. Monistettu objekti ei saa pitkään olla ainutkertainen eikä enää edes status nascende. On ehkä sattuma, että banaalin taiteellinen käyttö esimerkiksi readymade objektina Marcel Duchampilla tai automaattisena kirjoituksena Andre Bretonilla ja surrealisteilla (ks. Sami-Alin erinomainen analyysi teoksessa $L e$ Banal) keksittiin melkein samanaikaisesti joukkotiedotuksen esiinmarssin ja läntisten suurkaupunkien liikennetekniikan kanssa. Andy Warhalin poptaide ja sen johdannaiset ovat puolestaan taiteellinen oire oman "monistemaailmamme" (Xerox Galaxy) vahvuudesta ; se ei ole vain säilyttänyt sädekehäänsä vaan se on myös parodisesti joskin redundantisti uudistunut ja osoittanut samalla aiemman mitättömyytensä ja puutteellisuutensa. Nykyään emme enää siis tunnista hyvää tai huonoa taidetta vaan pelkästään hyvän ja huonon jäljennöksen - mikä on loppujen lopuksi vain hyvää tai huonoa banaalisuutta.. Ja kuten hittilistan mekanismi selvästi osoittaa, ainutkertainen muuttuu pian banaaliksi, ts. uudesta tulee pian vanhaa: tällöin se ikääntyy ja kuolee.

Italialainen esteetikko Gianni Garchia analysoi hienossa esseessään L'estecia della decadenza modernisuuden, vanhenemisen ja kuoleman välistä suhdetta seuraavasti:

... vanheneminen on aina yhteydessä uutuuteen. Modernisuuden käsite sisältää myös melkein kirjaimellisesti ajatuksen vanhenemisesta, muodin ja kuoleman kohtaamisesta. Vain aivan tietyssä modernisuuden mielessä, uusi määritellään yhden ja saman merkin, sen vastapoolina olevan menneisyyden avulla. Uusi on 
se mikä virtaa ohi, se mikä syntyy kuollaakseen pois, se mikä on tarkoitettu poistettavaksi. Modernisuuden logiikan mukaan vanha ei ole niinkään ohimennyttä, toisin sanoen se on pikemmin menneen ajan ulottuvuus kuin katoavan uutuuden perusominaisuus. ( Garchia 1982, 107).

Garchia $(1984,22)$ sanoo toisaalla, että "ikääntyminen on ajan modernisuuden aktivointia muistina". Toisin sanoen vanhenemisen käsite ei viittaa vain fyysiseen tai fysiologiseen tilaan vaan myös modernisuuden sisältämään historialliseen tietoisuuteen sekä dekadenssin tunteeseen, joka syntyy muistin, nimenomaan lähimuistin katkoksesta. Muisti ei pidä vaan se pettää. Garchia jatkaa: "modernissa uusi voidaan määritellä väistyväksi, mikä ei kuitenkaan tarkoita että päättymässä olevan kokeminen on samaa kuin niin sanotun 'luonnollisen' kuoleman kokeminen". Modernisuus on siis nimenomaan luonnollisen väliaikaisuuden keinotekoinen rakenne, joka voidaan ennakoida (ibid. 1982, 108). Siksi modernisuuden esteettinen taju toimii dekadenssin tai rappion pohjalta. Romanttinen ennui (ikävystyminen) ja sen laitostuminen 1800-luvulla dandyismiksi, keikarillisuudeksi (Zijderveld 1979, 82; ks. myös Hughet 1984, luvut 1 ja 4) ovat, kuten Benjamin esittää, oireita modernisuuden kypsymisestä 1800-luvulla. Edelleen vanhenemista ja kyllästymistä esiintyy usein kun kohde tuntee että ajan kulu ei enää ole mitä se todella on, ts. kun esteettinen objekti, häipyessään viehtymyksen ja hetkellisen "järkkymisen" näköpiiristä (kuten André Breton määrittelee tämän kauneuden), kadottaa viehätysvoimansa. Näin ollen vanheneminen kauneusarvojen tajuamisen rappiona on väistämätöntä seurausta siitä, että uutuuden estetiikka tähtää vain hetkelliseen nautintoon. Onnen maailma joka kestää vain kolme minuuttia on juuri hittilista.

Hittisävelmän vanheneminen voidaan selittää kuulijoiden kyllästymiseksi, kun taas uuden musiikin (Neue Musik) vanheneminen, kuten Adorno huomauttaa, liittyy avant-gardistisen tekniikan ja sävellystyylin tuloon. Toisin sanoen yleisön havaitsemistapa on popmusiikissa relevantimpaa kuin tekniset ja sävellykselliset seikat. Jos ammattimaisuuden aste on sopiva kriteeri avant-garde -musiikille, on yleisön vastaanotto tai suosio taas vastaava kriteeri popmusiikille. Hitistä tulee "seniili" tai toimintakyvytön kun se ei herätä enää huomiota ja kun yleisö tajuaa että sävelmän soundi on jo menettänyt sisäisen voimansa. Kun ihailijat kuulevat hitin ensimmäiset sävelet, he vaistomaisesti tunnistavat onko sen viehätys jo kadonnut, onko hitti menettänyt merkityksensä vai ei. Kyllästyminen on tyypillisesti "subjektiiviseen ajankokemiseen" liittyvä piirre" (Zijderveld 1979, 77), ja sen pohja on "juuri modernin yhteiskunnan ja modernin tietoisuuden perusta". Modernisuus, jatkaa Zijderveld analyysiään, aiheuttaa sen että objektiivinen (kellolla mitattava) aika syrjäyttää subjektiivisen ajan (aika ohikulkevana, aiempiin kokemuksiin liittyvänä kestona). Toisin sanoen nykyihmisen täytyy tietää haluaako hän välttää ikävystymistä ja mitä hänen pitäisi tehdä kellon mittaamalla ajallaan. Ihmisen pakkomielle täyttää normaaliaikansa tekemisellä onkin läheistä sukua maaniselle uutuudenkaipuulle (neomania); ikävystymistä, joka saa subjektiivisen ajan "tuntumaan siltä että se kestäisi ikuisesti" (ibid., 77), ei voi verrata uutuudenviehätykseen, joka kestää vain hyvin lyhyen ajan. Kyllästyminen subjektiivisen ajan tasolla voi olla 
sosiaalisesti tuhoisaa, se voi viedä ihmisiltä kommunikaatio- ja vuorovaikutuskyvyn. Baudelaire varoittikin että "ikävystynyt ihminen tuhoaisi sumeilematta maailman jos vain voisi" (ibid., 77).

Jos katsomme laiskuuden ihmisen omaksi valinnaksi, hänen yrityksekseen ottaa välimatkaa siihen mitä elävässä elämässä tapahtuu, näyttää ikävystyminen olevan etäytymistä (tai vieraantumista) ilman omakohtaista suhdetta tai osallisuutta todellisuuteen (mikä on tylsää on tylsää). Laiskuudesta ja ikävystymisestä johtuva velttous on modernisuuden äärimuoto, kuten P. Virillo (1980) huomauttaa viitatessaan Howard Hughesin viimeisiin vuosiin, jotka voidaan tietyssä mielessä nähdä jälkimodernistisena tilana. Aivan kuten amerikkalaisen miljonäärinkin tapauksessa, jossa mies vaipuu keinotekoiseen talviuneen, ikävystyminen samoin kuin velttouskin ovat olotiloja jotka merkitsevät modernin yhteiskunnan asteittaista rappiota, toisin sanoen lähestyvää kuolemaa. Ja juuri tältä meistä tuntuu kun seuraamme hittilistan ykkösen putoamista Top 40:ssä. Listasävelmien nousut ja laskut siis osoittavat, että ikävystyminen vaatii vastapainokseen järkytyksiä - jotakin uutta, outoa - joka kykenee poistamaan sen: "Ikävystynyt ihminen tarvitsee näiä kehon, psyyken ja mielen ärsykkeitä koska hänen käyttäytymisensä ei saa muita yllykkeitä. Näistä ärsykykkeistä tulee modernissa yhteiskunnassa kollektiivisia liikkeitä, mikä johtuu tiedotusvälineiden uutisnälästä ja erityisesti kaupallistumisesta (ibid., 84).

Lienee tarpeetonta sanoa, että enin osa järkytyksistä pakosta lieventyy ja suodattuu vielä voimakkaampien järkytysten takia. Lopulta ärsykekynnys kasvaa niin korkeaksi, ettei ihmistä heilauta enää mikään. Äärimmäisen eriytymisen äärimuotona on siis täydellinen yhdenmukaistuminen. Simmeliläinen ristiriita näiden kahden vastakkaisen pyrkimyksen välillä voitaisiin sulauttaa yhdeksi: tasapäistymiseksi ja samankaltaistumiseksi. Vaikkakin banaali on "esteettisesti merkityksetöntä" (Rosenkrank 1984, 178), musiikin valtavirta peittyy sen alle. Mainstream on kuitenkin loppujen lopuksi banaalia ja tavanomaista, ja näin on hittilistankin laita, koska ainoastaan mainstream kelpuutetaan siihen mukaan.

Olemme tässä ehkä painottaneet liikaa hittiparaatin "pimeää" puolta. Tiedämmehän toisaalta, että hittilistalla on kyky vietellä romanssiin, mitä I. Chambers pitää "keskeisenä koko popin kulttuuritaloudelle" $(1958,127)$. Popmusiikki on oma vaihtoehtoinen tai muuntunut todellisuutensa, ja se rakentuu hajallaan olevista sävelmistä, jotka ovat peräisin moninaisesta ja pirtoutuneesta kokonaisuudesta. Chambers toteaa että "populaarikulttuuri on levittäytynyt muovikelmun tavoin arkitoimiemme ja -elämämme pinnalle, ja se yhdistää ne ilmeisen proosallisiksi kaavoiksi. Toisaalla pop on sinnikkästi tarjonnut koko maailman kattavan takuun tanssille, sänkykuvitelmille, viihdetarinoille, selvemmin sanottuna näille lukemattomille yksilöllisen vakuuttelun muodoille, jotka reunustavat jokapäiväistä elämäämme." (ibid.).

Hittiparaati onkin yksi tärkeimpiä romantiikan komponentteja, joista esimerkkinä Chambers mainitsee nimikirjoituksin varustetut suosikkikuvat ihailijakerhon jäsenlehdessä, tähden kuvalla varustetut erilaiset kapineet jne. Se on tärkein menestystarinan ruokkija, ja se tarjoaa auliisti kriteerin "populaarisuudelle" määrien ja numeroiden tasolla. Voisimmekin sanoa että menestystarina ei koskaan olisi mahdollinen ilman hittilistan tarjoamaa tukea. Oikeastaan 
juuri hittilistan formalistinen dynamiikka tekee menestyksen ei vain havaittavaksi (mitattavaksi) vaan myös mahdolliseksi. Sanomattakin on selväă, ettă jokaisesta menestystarinasta tulee heti kulunut, arkipäiväinen, lattea ja banaali. Se toistaa itseään. Se monistaa itseään. Ainut yksilöllinen piirre tuossa viihdetarinassa on mahdollisesti tähden nimi kuten Springsteen, Jagger, Jackson tai Prince. Ja kuten semioottiset analyysit viihdetarinan kerronnallisesta rakenteesta voisivat osoittaa, tăhtitarina on aina sama tähden nimeă lukuunottamatta. Tässă vain erisnimen osoittava funktio ja viittausvoima loogis-lingvistisessä mielessä tai yksinkertaisesti sen formaalisuus voivat tehdä samat tarinat mahdollisiksi ja puoleensavetäviksi.

Hittilistan kaavamaisuus on siis päivänselvää. Sehän käsittelee vain päivămääriä, kappaleiden ja esittäjien nimiä, sijalukua, luodinomaista nousua jne. Mikään musiikillinen sisältö tai mahdollinen "merkitys" ei ole relevantti ohjaamaan hittilistaa sellaisenaan. Ja jos merkin sisältö on yhtä kuin sen käyttöarvo ja merkin vaihtoarvo yhtä kuin sen sisältö, kuten Baudrillard eräässä varhaisessa kirjoituksessaan huomauttaa, hittilista on tarkasti vaihtoarvon neliö. Siinähän lasketaan kirjainyhdistelmien, rahan ja levyjen frekvenssiä, joihin popfanit ovat sijoittaneet "minimipääomaansa". Hitin kollektiivinen viehätysarvo ilmaistaan numeromuodossa yhtä tarkasti kuin osakekurssit pörssin valotaululla. Listassa seuraamme hittisävelmän nousua ja laskua tietämättă silti selvästi, mikä sävelmä on, mitä se merkitsee todellisuudenkuvallemme ja tajunnallemme, mikä on sen sisältö. Se vain ilmestyy näkyviin ja katoaa, tulee ja menee.

Hittisävelmän sisältö vaikuttaa sävelmän heilahteluun văhemmän kuin sen muoto. Niinpä jos hittilista on malliesimerkki musiikin kapitalistisesta olemuksesta, tämä johtuu siitä, että muodon ensisijaisuus (vaihtoarvon, funktion, nimen...) ohjailee sen dynamiikkaa.

A. C. Zijderveld, joka määrittelee klisheen "merkityksen korvaamiseksi funktiolla", väittää että klisheen muodon tyhjyys (muoto ilman sisältöä) on tyypillistä sille mitä hän kutsuu klisheevaltaiseksi (clichégenic) yhteiskunnaksi; tällaiselle yhteiskunnalle on luonteenomaista sosiaalisten käytäntöjen automatisoituminen (byrokratia ja poliittiset iskulauseet ovat Zijderveldin pääesimerkkejä) ja teknologinen joukkotiedotus, joka suosii ja tarvitsee mainittua automatisoitumista; niistä syntyy muotti jolle loputtomasti toistava tuotanto (ja uusintaminen) sitten perustuvat. Hän huomauttaakin että "klisheitä on helppoa niellä koska ne eivät vaadi älyllistä ajattelua" (s. 12). Musiikin kohdalla voimme soveltaa ajatusta seuraavassa muodossa: hittisävelmät eivät vaadi esteettistä ajattelua. Hittilistassahan toteutuu sisällön korvautuminen muodolla, ts. se että jokaisen sävelmän päällimäisenä merkityksenä on päivämäärä, numerosija, nimellinen sijoitus.

Hittilistan estetiikka ei ole siinä, että musiikkikappaleita johdonmukaisesti arvioitaisiin esteettisinä ja pysyvinä objekteina, vaan siinä että sävelmä välittömästi, hetkellisesti ja pinnallisesti tajutaan (tai vaistotaan) rappeutuvaksi, vanhenevaksi objektiksi. Tämä ei synny älyllisestä ajattelusta tai pohdinnasta vaan salamannopeasta ja pakonomaisesta viehättymisestä: tämä viehättyminen on hetkellisyyden, katoavuuden ja kuoleman lumoa. Se on "taistelua mielihyvän takia" (Wim Mertens), ja vaikka se liittyykin tiiviisti freudilaiseen dikotomiaan, 
sitä ei voi myöskään erottaa modernista kuoleman käsitteestä. Niinpä sikäli kun popmusiikki on "sitä muodostavien kategorioiden kysyvää kokeilevaa liikettä" (Chambers, ibid. 209) eikä pakoa todellisuudesta, millaisena sitä on tässä kirjoituksessa tähän asti lähestytty, ja sikäli kun banaali, halventavasta sivumerkityksestään huolimatta, rakentaa sopivasti päivittäistä elämää (Berger ja Luckmann), hittilistan kaksijakoisen aseman on täytynyt syntyä myöhäiskapitalistisessa - ja siten dromologisessa (Virilio) - yhteiskunnassa nopean elämän, hetkellisen nautinnon ja erityisesti lähestyvän kuoleman sivutuotteena : mielihyvä lykkää kuoleman tuonnemmaksi, mutta se on kuitenkin edessä, ennemmin tai myöhemmin.

\section{Lähteet}

Adorno, Theodor W.

1949 Philosophie der Neuen Musik. Frankfurt am Main: Suhrkamp.

1963 Die Dissonanzen. Suhrkamp: Frankfurt am Main.

Barthes, Roland \& Jean-Louis Bouttes

1979 "Luoco comun", In: Enciclopedia Einaudi, vol. 8.

Baudrillard, Jean

1972 Pour une critique de l"économie politique du signe. Paris: Gallimard.

Campagnon, Antoine (ed.)

1978 Prétexte: Roland Barthes. Paris: U.G.E.

Carchia, Gianni

1982 La legittimazione dell"arte. Naples: Guida editori.

1984 "Per una estetica dell" invecchiato", In: Dame e cavalieri nel Balon di Torino. Milan: Mondadori.

Chambers, Iain

1985 Urban rhythms. London: Macmillan.

Grossberg, Lawrence

1982 "Politics of youth culture": Some observations on rock and roll in American culture. (unpublished manuscript).

1985 "If rock and roll communicates, then why is it so noicy?" In: Proceedings of the 2nd congress of IASPM at Reggio 1982. (In print).

Hughet, Michèla

1984 L'ennui et ses discours. Paris: P.U.F.

Rosenkranz, Karl

1984 (1853) Estecia del Brutto ( orig. Aesthetik des Hässlichen, translated by Maria Zinanni). Bologna: Mulino.

Samili-Ali

1980 Le banal. Paris: Gallimard.

Simmel, Georg

1983 (1911) Philosophische Kultur. Berlin: Wagenbach. (Suomeksi George Simmel,Muodin filosofia, suom. Antti Alanen, Helsinki: Kustannus Oy

Virilio, Paul Odessa, 1986).

1980 Esthétique de la disparition. Paris: Balland.

Zijderveld, Anton C.

1979 On clichés.London etc.: Routledge \& Kegan Paul. 


\section{Summary}

\section{The fascinating banality of the hit parade}

The hit parade is a universal phenomenon in modern popular music. In the hit parade, a rapid oscillation of taste takes place, and this is connected with the phenomenon called "fashion" or "style". Pop music has no past, no future, no survival: it is the music of this week, today and this moment, and this is why a sense of "nowness" is its crucial aspect.

In pop music we must deal with the banal based on the singular and the singular based on the banal; these are two extremes in a continuum of aesthetic judgements. The ups and downs of a tune in a hit parade result from the banalization of the singular, from the familiarization of the strange and the aging of the new.

The fluctuation of tunes is also affected by what Simmel calls "an aesthetic fascination". The fashion evokes a fascination that simultaneously begins and ends, the fascination of the new and simultaneously of the past.

The artistic use of the banal, such as the ready-made objects of Marcel Duchamp and the automatic writing of Andre Breton and the surrealists appeared almost simultaneously with the rise of the mass media. Andy Warhol's pop art is an artistic symptom of the establishment of our Xerox galaxy. Nowadays we do not consider whether something is good art or bad art, but whether it is "good repetition" or "bad repetition", which is basically good banality or bad banality. In the case of a hit parade, the former soon becomes the latter, while the new becomes old, aged, and finally dies.

The concept of aging is tied to the historical consciousness of modernity and the notion of "decadence", which appeared in the nineteenth century as romantic ennui (boredom) and its institutionalization, dandyism. Aging as an aesthetic decay results from the aesthetics of the new in search of instant pleasure.

The aging of a hit tune is connected with the boredom of its listeners. Boredom as such is a modern phenomenon; modern man wishes to avoid boredom and thus is obsessed with filling up his time. This takes the form of a manic pursuit of the new, a neomania. While laziness is a personal choice of distancing oneself from what is going on in the world, boredom is a type of alienation without a conscious effort by the person. In a way, boredom as well as idleness mean the gradual death of modern society.

The aesthetics of the hit parade does not lie in the appreciation of a musical piece as an enduring aesthetic object but in the instantaneous, momentary and ephemeral sensation of the object in decay, in its process of aging. The hit parade is a phenomenon that does not demand any reflection. It is merely based on instant fascination, and this is the fascination of evanescence, disappearance and death. 